\title{
Integrating Operations and Marketing in the Fast Food Delivery Industry
}

\author{
Saad Shahid* and Shamila Nabi Khan ${ }^{* *}$
}

\begin{abstract}
The purpose of this study is to find out how marketing and operations integrate to provide high-quality fast food delivery service. Based on survey data for three different restaurants that offer a telephone ordering service, we analyze the degree and strength of integration between marketing and operations and the relationship with customer behavioral intention. The results show that telephone customer care quality has a direct relationship with product quality and service quality. Both product and service quality have a significant relationship with consumer behavioral intention. We develop a model that integrates marketing and operations with accessibility and consumer attitudes to telephone ordering as moderator variables. Finally, the study suggests that each sample restaurant has a different operational strategy and needs to focus on different business factors.
\end{abstract}

Keywords: Marketing, operations management, operations, interaction.

JEL classification: C12, C42, L81, M31, M37.

\section{Introduction}

As the fast food delivery service industry continues to thrive, companies are compelled to develop new and improved technologies and methods to integrate operations and marketing efforts (Schlosser, 2012). Telephone ordering links home-based customers to fast food restaurants and is one way of integrating operations, marketing and sales (Olsen, 2004). This study examines the market for telephone ordering and fast food delivery services where marketing operations and strategies need to be carefully synergized. We survey three fast food restaurants with distinctly different operations and marketing strategies for delivering food to their customers. Based on the survey data provided by their customers, we investigate the relationships among marketing, operations and customer satisfaction.

\footnotetext{
* Teaching fellow, Lahore School of Economics.

** Teaching fellow, Lahore School of Economics.
} 
When consumers prefer the convenience (Glanz et al., 1998) of food delivered to their doorstep, it is important to ensure that companies meet or exceed the expectations associated with their marketing initiatives. This can only be done if marketing and operations are effectively integrated, which in turn reduces companies' delivery time (Teimoury \& Fathi, 2013)..$^{1}$ Many fast food delivery restaurants have learned the hard way how important it is to integrate the process of receiving a telephone order and delivering the product ordered. The first challenge is logistical: the food must be delivered within a particular timeframe. As their marketing communications indicate, the delivery window used by global fast food chains is 30 to 45 minutes. The tighter this window becomes, the greater the challenge for the company. The aim of offering a delivery service is to provide a wide range of consumer services without the consumer having to come to the restaurant, place an order and take it away. This incorporates consumer convenience, but at the same time poses an operational challenge for the company (Lee \& Whang, 2001).

As an example, we take the case of the restaurant Burger Hub, which was unable to coordinate its marketing and operations strategies. While it promised a complementary delivery service within a 45-minute window, the company took between 1 and 1.5 hours to reach the consumer. At best, the consumer was left unhappy with the service; at worst, the order was cancelled. The delay in service delivery not only affected the company and the consumer at that point in time, but also cost the company any future sales associated with a loyal customer. Boyer and Hult (2005) explain that customers who experience better service quality will be more loyal and are likely to continue purchasing from a given company. Had Burger Hub relied less on offering a complementary delivery service to reduce costs and emphasized timely delivery instead, it could have targeted consumers who prefer convenience over cost.

Fast food chains such as Pizza Hut and KFC have achieved success by not rushing into the complicated process of providing a food delivery service. Pizza Hut markets itself as a high-quality pizza producer that guarantees fast, oven-hot delivery. In contrast, KFC markets attributes such as quick delivery and product offers to lure consumers into buying more. Increasingly, firms are competing on the basis of response, delivery and shipping time. Many firms now choose to announce a guaranteed maximum service delivery time to attract customers (Ho \& Zheng, 2004).

\footnotetext{
${ }^{1}$ See also Tang (2010); O’Leary-Kelly and Flores (2002); Ho and Zheng (2004); Ray (2005); Feng, D'Amours and Beauregard (2008); Ioannidis and Kouikoglou (2008); Rao (2009); Vandaele and Perdu (2010); Erickson (2011); Oliva and Watson (2011).
} 


\section{Literature Review}

Operational elements are those activities service providers perform that contribute to consistent quality, productivity and efficiency. These comprise the physical features of the service, that is, the characteristics of delivery that define and capture form, time and place. Operational service, for example, consists of elements such as product availability, product condition, delivery reliability and delivery speed.

Relational elements include those activities that enhance the service firm's understanding of its customers' needs and expectations, based on which it develops processes to meet these (Stank, Crum \& Arango, 1999). This can include personnel or information systems to facilitate frequent communication and enable suppliers to better understand the firm's customer environment. Successful service firms perform well on both fronts: they understand customers' needs and expectations and are able to provide a corresponding level of service quality and efficiency (Schlesinger \& Heskett, 1991).

Physical distribution includes the processes that support the flow of materials and related information from the point of origin (the stocking location) to the point of consumption (the consumer's location) (Lambert \& Stock, 1993; Mentzer, Gomes \& Krapfel, 1989). Cronin, Brady and Hult (2000) emphasize the importance of integrating marketing and operations in the services sector. Based on a model incorporating six service industries (healthcare, fast food, entertainment, spectator sports, long-distance sports and participative sports), they demonstrate the significant, direct path from value to intentions in all these industries and the significant, indirect path from value to satisfaction to intentions in most industries.

Zeithaml (1988) characterizes value as meaning a "low price," "whatever I want in a product," "the quality I get for the price I pay," and "what I get for what I give." She argues that these four meanings can be applied collectively such that "perceived value is the consumer's overall assessment of the utility of a product based on the perception of what is received and what is given."

In an innovative study on retail banks, Roth and Van Der Velde (1991) identify key success factors or service-related competitive priorities, three of which are relevant across service industries: (i) courteous service, (ii) consistent service and (iii) enlarging customer relationships. While the first and third relate to marketing, the second concerns operational 
performance. Zeithaml, Berry and Parasuraman (1996) suggest that positive behavioral intention (BI) is reflected in the service provider's ability to persuade its customers to remain loyal, pay price premiums and communicate their concerns to other customers as well as to the company.

Clearly, there is likely to be a relationship between customer experience and $\mathrm{BI}$ that takes the shape of repeat purchases. In examining the relationship between customer experience and BI, we divide customer experience into three subsets - the quality of telephone customer care, products and service - which is where the study adds value to the literature.

Delivery service quality is the extent to which the customer's perceived delivery time matches the expected delivery time. Specifically, it is the probability that the perceived delivery time is shorter than the expected maximum delivery time (Ho \& Zheng, 2004). The customer's perceived delivery time is 15 to 30 minutes - the period in which food can still be served fresh and while the customer is hungry. We use constructs such as service quality and BI to gauge whether delivery quality affects the consumer's intentions.

Boyer and Hult's (2005) model integrates marketing and operations in the online grocery industry, using moderating variables such as consumer attitudes and online accessibility as factors that affect customer BI. We build on this framework in the context of the fast food delivery industry. Intuitively, an online grocery ordering service adds consumer value in a way similar to fast food delivery services.

While both corporate and functional strategies are critical for an organization to be successful, we focus on the relationship between marketing and operations. Drawing on Narver and Slater (1990), responsive market orientation is a function of three subcomponents: (i) customer orientation (understanding the customer's needs and wants), (ii) competitor orientation (understanding competitors' strengths and weaknesses, and how they meet their customers' needs and wants), and (iii) inter-functional coordination (the coordinated use of the organization's resources to create superior value for customers) (Boyer \& Hult, 2005).

Our study aims to determine the extent to which marketing (customer orientation) and operations (inter-functional coordination) are integrated and how this affects consumer BI in Pakistan's fast food delivery 
industry. ${ }^{2}$ The idea that customers prefer higher service quality is intuitive, particularly if price and other cost elements are held constant. Additionally, equity theory suggests that customers who perceive that an organization's delivery service quality is accompanied by better-quality ingredients, for example, are more likely to attribute greater equity to their relationship with that organization (Kelley \& Davis, 1994).

Service firms that value customer closeness may be able to provide higher levels of effective service (Reichheld \& Sasser, 1990; Schlesinger \& Heskett, 1991; Reichheld, 1996). Customer satisfaction is considered the cumulative evaluation of a customer's total purchase and consumption experience of a good or service over time (Fornell, 1992; Fournier \& Mick, 1999). We take this a step farther by adding the construct consumer intentions and bringing in two distinctly different functions: marketing and operations.

Most fast food delivery service companies fail to strike a balance between marketing and operations when they are unable to align business strategies with customers' needs and wants. Our research questions are derived from the literature on marketing and operations in different industries. However, no other study has examined the integration of marketing and operations strategies in the fast food delivery industry in Pakistan, which represents a relatively new market for this sector. When consumers prefer convenience over all other attributes of the product, it becomes necessary to develop a suitable mix of marketing and operations. We study this against the backdrop of the growing number of restaurants in Pakistan that offer fast food delivery services.

\section{Research Framework and Hypotheses}

We analyze three primary constructs: telephone customer service quality (TSQ), product quality (PQ) and service quality (SQ). All three constructs are related to marketing and operations. The basic premise is that the fast food delivery industry is becoming fiercely competitive and that companies must now integrate both these aspects to achieve business success.

\subsection{Telephone Customer Service Quality}

The first hypothesis takes into account the role of TSQ and its relationship with $\mathrm{SQ}$ and $\mathrm{PQ}$ in the fast food delivery industry. One of the

\footnotetext{
${ }^{2}$ See Boulding, Kalra and Staelin (1999); Cronin and Taylor (1992); Zeithaml et al. (1996).
} 
biggest concerns in telephone ordering is the fundamental shift from the traditional process of physically going to a restaurant to select and purchase food to providing it directly to the consumer at home. From a corporate point of view, this is a greater operational challenge because the company is essentially taking back work that was previously self-sourced by the customer (Yrjola, 2001).

In the absence of a model that integrates marketing and operations in Pakistan's fast food delivery industry, we develop one that draws on existing models of TSQ and online purchasing. From the customer's perspective, ordering food on the telephone is fundamentally different from walking into a restaurant. The firm must process the customer's order while ensuring that it is delivered in time and still meets certain quality standards. We examine the premise that companies must facilitate their customers by (i) providing a simple, understandable helpline service and (ii) making transactions as easy and transparent as possible while delivering the product according to customers' needs and wants within the promised window.

We analyze TSQ based on ease of use, which is an important indicator of customers' adoption of and satisfaction with fast food delivery service (Agarwal \& Prasad, 1999). Perceived ease of use includes elements of marketing (customer perceptions) and operations (the company's ability to meet customers' expectations while incurring the lowest possible cost). Several studies demonstrate the link between user satisfaction and TSQ factors (see Gwinner, Gremler \& Bitner, 1998; Harris \& Goode, 2004). It is fair to assume that customers who are more comfortable accepting and understanding the ordering process will make fewer mistakes when placing an order and will indicate higher levels of satisfaction. Moreover, if customers fully understand what the restaurant has to offer in terms of value for money, they will have a positive perception of its SQ and PQ. Based on this discussion, we test the following hypotheses:

- H1a: The quality of XYZ's ${ }^{3}$ telephone customer care (TSQ) is positively related to $\mathrm{SQ}$ in a fast food delivery service.

- H1b: The quality of XYZ's telephone customer care (TSQ) is positively related to $\mathrm{PQ}$ in a fast food delivery service.

\footnotetext{
${ }^{3} \mathrm{XYZ}$ represents the three different fast food brands we have surveyed: A, B and C.
} 


\subsection{Product Quality}

The second hypothesis considers the role of PQ in consumer $\mathrm{BI}$ when using a fast food delivery service. The impact of service-encounter constructs such as the physical quality of the good, the quality of service provided and the scope of service is widely researched (see Lovelock, 1983). Crosby (1979) defines quality as "conformance to requirements." When the consumer's product requirements meet his/her needs and wants, he/she is deemed satisfied with the quality of the product. Quality itself is composed of the core quality (what is delivered) and relational quality (how it is delivered) with various levels of tangible and intangible elements (McDougall \& Levesque, 2000).

The quality of the food is the most important element affecting customer satisfaction and re-patronage intentions in a full-service restaurant (Sulek \& Hensley, 2004). If we look at customer satisfaction as a cumulative evaluation of the consumer's total purchase and consumption experience of a good or service over time (Fornell, 1992; Fournier \& Mick, 1999), we can gauge how positive BI is reflected in the firm's ability to persuade its customers to remain loyal (Zeithaml et al., 1996). More experienced customers will express their BI by making repeat purchases. Based on this, the second hypothesis is:

- H2: The PQ offered by XYZ is positively related to a customer's BI of using fast food delivery services in the future.

\subsection{Service Quality}

There is significant support in the literature for the link between SQ and consumer BI (see Boulding et al., 1999; Zeithaml et al., 1996). The concept that customers seek greater SQ is intuitive, particularly if price is held constant. In this case, we define delivery quality as the probability that the customer's perceived delivery time is shorter than the expected maximum delivery time (Ho \& Zheng, 2004). Thus, a higher level of SQ will increase customer satisfaction (Crosby, Evans \& Cowles, 1990; Innis \& La Londe, 1994; Zeithaml et al., 1996). As above, customer satisfaction is seen as a cumulative evaluation of the total purchase and consumption experience over time (Fornell, 1992; Fournier \& Mick, 1999).

Given that firms compete increasingly on the basis of response, delivery or shipping time, we cite the conventional wisdom that a firm's commitment to providing timely delivery can be a powerful competitive 
advantage if the service guarantee represents a breakthrough in service and the firm is able to fulfill this guarantee reliably (Ho \& Zheng, 2004). As before, we assume that more experienced customers express their BI by making repeat purchases. Based on the discussion above, the third hypothesis is:

- H3: The SQ offered by XYZ is positively related to a customer's BI of using fast food delivery services in the future.

\subsection{Customer Attitudes and Accessibility}

Telephony spans diverse information systems to enable accurate, widespread and low-cost communication (Harris \& Goode, 2004). Over the years, it has become an integral means of interaction in retail markets (Bailey, 1998). In line with Agarwal and Prasad (1999), we examine the moderating role of technology using two variables: (i) customer attitudes toward telephone ordering (ATT) and (ii) accessibility or ease of access (EA), which gauges whether the helpline is answered quickly and is available at the user's discretion (Boyer \& Olson, 2002). Accordingly, we test the following hypotheses:

- H4: ATT moderates the relationships in $\mathrm{H} 1-\mathrm{H} 3$ as well as a customer's BI of using fast food delivery services.

- H5: EA moderates the relationships in $\mathrm{H} 1-\mathrm{H} 3$ as well as a customer's BI of using fast food delivery services.

\subsection{Research Framework}

Based on the hypotheses above, Figure 1 presents an overview of our research. 
Figure 1: Integration of operations and marketing in the fast food delivery industry

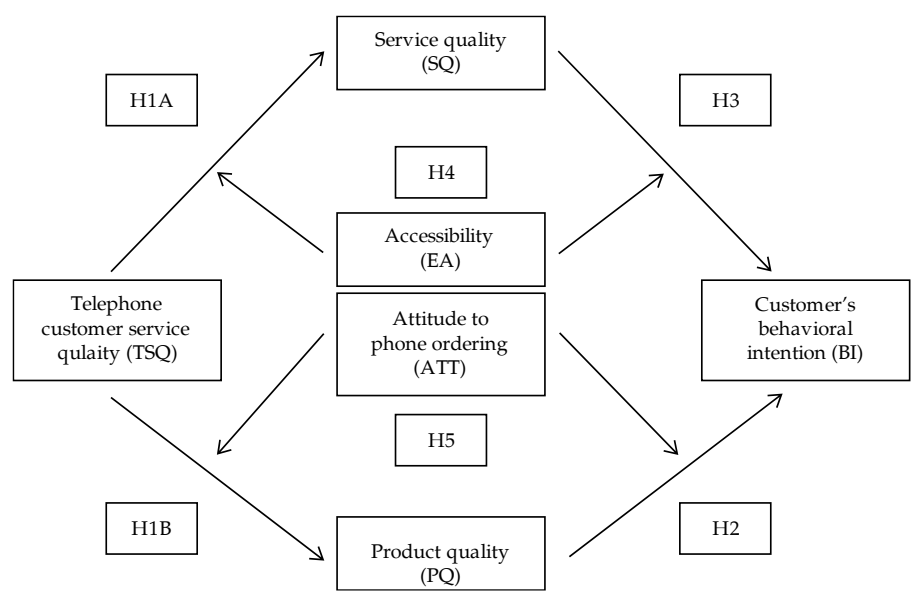

\section{Dataset, Methodology and Variables}

The sample consists of customers who patronize three different fast food delivery service restaurants in Pakistan. All three restaurants are large multinational food chains denoted by A, B and C (see Appendix). Table 1 shows the basis on which the sample restaurants were selected and the differences in their product categories and marketing and operations strategies. The shortlist comprised multinational firms that provide a food delivery service, while their marketing communications include both operational and marketing content. Two independent experts from the restaurant industry, with more than 15 years' experience, were asked to narrow down the choice of fast food restaurants to three.

The overall sample consisted of 332 customers from Lahore, but was narrowed down to 200 customers who reported purchasing from one of the sample restaurants at least once a month (see Table 2 for details). All the data was collected between January and March 2013 over the course of two weeks per subsample.

Table 1: Selection of subsamples

\begin{tabular}{ccccc}
\hline Restaurant & Multinational & $\begin{array}{c}\text { Product } \\
\text { category }\end{array}$ & Marketing & Operations \\
\hline A & Yes & Burgers & Convenience & Product quality \\
B & Yes & Burgers & Quick delivery & Offers available \\
C & Yes & Pizza & Quick delivery & Oven-hot pizzas \\
\hline
\end{tabular}


Table 2: Data collection methodology and response rates

\begin{tabular}{lcccc}
\hline & Overall & A & B & C \\
\hline Customers contacted & 332 & 138 & 92 & 102 \\
Response received & 200 & 77 & 55 & 68 \\
Response rate (\%) & 60.2 & 55.8 & 59.8 & 66.7 \\
Data collection method & NA & Intercept survey & $\begin{array}{c}\text { Mall intercept } \\
\text { survey }\end{array}$ & $\begin{array}{l}\text { Intercept survey } \\
\end{array}$ \\
\hline
\end{tabular}

Source: Authors' calculations.

The survey was based on a self-administered questionnaire (see Appendix). At A and C, customers at the checkout point were asked to fill out the questionnaire. At $B$, we approached customers inside the mall but outside the restaurant itself, which did not allow surveys to be conducted inside. Out of a total of 332 customers approached at the three restaurants (138, 92 and 102 at A, B and C, respectively), 200 completed the questionnaire (77, 55 and 68 at $\mathrm{A}, \mathrm{B}$ and $\mathrm{C}$, respectively). This implies a response rate of about 56 percent for $\mathrm{A}$, about 60 percent for $\mathrm{B}$ and about 67 percent for $\mathrm{C}$. The average response rate was 60.2 percent for the collective sample.

Three categories of variables are used to test the hypotheses: quality measures (PQ, SQ and TSQ), performance measures (BI) and moderating variables (EA and ATT). ${ }^{4}$ All three quality measures were specifically selected to determine the integration between marketing and operations. PQ is an operational concern, TSQ relates to marketing and operations, and SQ is a marketing concern. TSQ is measured by seven items adapted from Agarwal and Prasad (1999) and Boyer and Olson (2002). SQ is measured by ten items proposed by Hartline and Ferrell (1996). PQ is measured by six items adapted from Brucks, Zeithaml and Naylor (2000) and Garvin (1988).

A restaurant that offers high levels of TSQ, PQ and SQ is more likely to encourage customer loyalty, which we measure using BI. Five items are used to determine BI. In line with the literature, a positive BI is reflected in a firm's ability to persuade its customers to remain loyal and promote its goods and services by word of mouth (Zeithaml et al., 1996). Finally, two constructs, ATT and EA, are expected to affect BI either directly or as moderating variables.

\footnotetext{
${ }^{4}$ A moderating variable represents a process or factor that alters the impact of the independent variable $\mathrm{X}$ on the dependent variable Y (Olsen, 2004).
} 


\section{Empirical Results}

This section presents the results of the regression analysis for the overall sample as well as for the individual subsamples.

\subsection{Correlation Analysis}

Table 3 shows the overall correlation between the variables. Both TSQ and PQ have a significant, positive relationship with all the variables ( $p$ $<0.01)$. The moderators EA and ATT are positive and significant $(p<0.01)$. BI has a positive, significant relationship with TSQ, PQ, SQ, EA and ATT ( $p$ $<0.01)$.

\section{Table 3: Pearson correlation results}

\begin{tabular}{lllllll}
\hline Construct & \multicolumn{1}{c}{ TSQ } & \multicolumn{1}{c}{ PQ } & \multicolumn{1}{c}{ SQ } & \multicolumn{1}{c}{ EA } & \multicolumn{1}{c}{ ATT } & \multicolumn{1}{c}{ BI } \\
\hline TSQ & 1.000 & $0.509^{* * *}$ & $0.344^{* * *}$ & $0.590^{* * *}$ & $0.285^{* * *}$ & $0.404^{* * *}$ \\
PQ & $0.509^{* * *}$ & 1.000 & $0.654^{* * *}$ & $0.418^{* * *}$ & $0.222^{* * *}$ & $0.514^{* * *}$ \\
SQ & $0.344^{* * *}$ & $0.654^{* * *}$ & 1.000 & $0.257^{* * *}$ & $0.170^{* *}$ & $0.450^{* * * *}$ \\
EA & $0.590^{* * *}$ & $0.418^{* * *}$ & $0.257^{* * *}$ & 1.000 & $0.297^{* * *}$ & $0.386^{* * *}$ \\
ATT & $0.285^{* * *}$ & $0.222^{* * *}$ & $0.170^{* *}$ & $0.297^{* * *}$ & 1.000 & $0.330^{* * *}$ \\
BI & $0.404^{* * *}$ & $0.514^{* * *}$ & $0.450^{* * *}$ & $0.386^{* * *}$ & $0.330^{* * *}$ & 1.000 \\
\hline
\end{tabular}

Note: ${ }^{* * *}$ significant at 0.01 level (two-tailed), ${ }^{* *}$ significant at 0.05 level (two-tailed). All correlations are significant at $p<0.01$. All items are measured on a seven-point Likert scale ranging from "strongly disagree" $=1$ to "strongly agree" $=7$. Shared variances are included above the diagonal.

Source: Authors' calculations.

Table 4 breaks down the correlation among the variables by A, B and C. For A, all the variables are highly significant at $p<0.01$ and $p<0.05$, apart from SQ and ATT. For B, all the coefficients are positive and highly significant with $p<0.01$ and $p<0.05$, apart from the relationships between SQ and ATT and PQ and ATT, which are both insignificant. For C, all the variables are significant and positive, apart from the relationships between SQ and TSQ, which is negative and insignificant, and between ATT and TSQ and SQ, which are insignificant. 
Table 4: Correlation among variables in subsamples

\begin{tabular}{lllllll}
\hline Construct & \multicolumn{1}{c}{ TSQ } & \multicolumn{1}{c}{ PQ } & \multicolumn{1}{c}{ SQ } & EA & ATT & BI \\
\hline A (N =77) & & & & & & \\
TSQ & 1.000 & $0.497^{* *}$ & $0.412^{* *}$ & $0.501^{* *}$ & $0.519^{* *}$ & $0.359^{* *}$ \\
PQ & $0.497^{* *}$ & 1.000 & $0.735^{* *}$ & $0.350^{* *}$ & $0.289^{*}$ & $0.434^{* *}$ \\
SQ & $0.412^{* *}$ & $0.735^{* *}$ & 1.000 & $0.402^{* *}$ & 0.200 & $0.391^{* *}$ \\
EA & $0.501^{* *}$ & $0.350^{* *}$ & $0.402^{* *}$ & 1.000 & $0.585^{* *}$ & $0.593^{* *}$ \\
ATT & $0.519^{* *}$ & $0.289^{*}$ & 0.200 & $0.585^{* *}$ & 1.000 & $0.475^{* *}$ \\
BI & $0.359^{* *}$ & $0.434^{* *}$ & $0.391^{* *}$ & $0.593^{* *}$ & $0.475^{* *}$ & 1.000 \\
B (N = 55) & & & & & & \\
TSQ & 1.000 & $0.630^{* *}$ & $0.547^{* *}$ & $0.717^{* *}$ & $0.319^{*}$ & $0.494^{* *}$ \\
PQ & $0.630^{* *}$ & 1.000 & $0.698^{* *}$ & $0.564^{* *}$ & 0.200 & $0.650^{* *}$ \\
SQ & $0.547^{* *}$ & $0.698^{* *}$ & 1.000 & $0.537^{* *}$ & 0.200 & $0.464^{* *}$ \\
EA & $0.717^{* *}$ & $0.564^{* *}$ & $0.537^{* *}$ & 1.000 & $0.281^{*}$ & $0.360^{* *}$ \\
ATT & $0.319^{*}$ & 0.200 & 0.200 & $0.281^{*}$ & 1.000 & $0.319^{*}$ \\
BI & $0.499^{* *}$ & $0.650^{* *}$ & $0.464^{* *}$ & $0.360^{* *}$ & $0.319^{*}$ & 1.000 \\
C (N $=68)$ & & & & & & \\
TSQ & 1.000 & $0.359^{* *}$ & -0.100 & $0.605^{* *}$ & 0.100 & $0.339^{* *}$ \\
PQ & $0.359^{* *}$ & 1.000 & $0.455^{* *}$ & $0.253^{*}$ & 0.200 & $0.479^{* *}$ \\
SQ & -0.100 & $0.455^{* *}$ & 1.000 & $-0.284^{*}$ & $0.252^{*}$ & $0.489^{* *}$ \\
EA & $0.605^{* *}$ & $0.253^{*}$ & $-0.284^{*}$ & 1.000 & $0.339^{* *}$ & 0.200 \\
ATT & 0.100 & 0.200 & $0.252^{*}$ & $0.339^{* *}$ & 1.000 & $0.540^{* *}$ \\
BI & $0.339^{* *}$ & $0.479^{* *}$ & $0.489^{* *}$ & 0.200 & $0.540^{* *}$ & 1.000 \\
\hline
\end{tabular}

Note: All correlations in each of the three samples are significant at $p<0.01$ and $p<0.05$. All items are measured on a seven-point Likert scale ranging from "strongly disagree" $=1$ to "strongly agree" $=7$. Shared variances are included above the diagonal.

Source: Authors' calculations.

\subsection{Measurement Statistics}

Table 5 gives the mean, standard deviation (SD), average variance extracted (AVE), composite reliability (CR), factor loading interval and discriminant validity for the overall sample $(n=200)$. To test for validity and reliability, we calculate the AVE, CR and discriminant validity. The factor loadings for all the variables are above 0.47 , due to which they are retained. Items with a loading of less than 0.4 are dropped.

Two types of validity are calculated: convergent and discriminant validity. The first is tested using the AVE. If the AVE is higher than 0.5, convergent validity holds, although a value of 0.4 is also acceptable. Discriminant validity is tested by comparing the AVE with the squared correlation (Fornell \& Larcker, 1981). Here, it is higher than the squared 
correlation (not shown in the table), which implies that discriminant validity holds for the overall sample. The cut-off point for CR is 0.7 , although some studies suggest that a value of 0.6 is also acceptable. Thus, discriminant and convergent validity and $\mathrm{CR}$ hold for the overall sample.

Table 5: Measurement statistics for overall sample

\begin{tabular}{lcccccc}
\hline Variable & Mean & SD & AVE & CR & $\begin{array}{c}\text { Factor } \\
\text { loading }\end{array}$ & $\begin{array}{c}\text { Discrimina } \\
\text { nt validity }\end{array}$ \\
\hline TSQ & 5.07 & 0.95 & 0.53 & 0.78 & $0.64-0.80$ & 0.709 \\
PQ & 5.04 & 0.99 & 0.50 & 0.86 & $0.47-0.87$ & 0.710 \\
SQ & 5.16 & 0.89 & 0.50 & 0.85 & $0.57-0.85$ & 0.730 \\
BI & 5.11 & 0.92 & 0.46 & 0.60 & $0.51-0.93$ & 0.727 \\
\hline
\end{tabular}

Note: $\mathrm{N}=200$. Reliability: the CR for ATT is less than 0.70 . Convergent validity: the AVE for ATT is less than 0.50 .

Source: Authors' calculations.

Table 6 presents a measurement analysis for each subsample. The factor loading for each item is higher than 0.4 . The validity and reliability values for $\mathrm{A}, \mathrm{B}$ and $\mathrm{C}$ are all above the cut-off figure suggested by Hair et al. (2006). The AVE is above 0.4, the discriminant validity is higher than the correlation squared (not shown in the table) and the CR is higher than 0.6.

Table 6: Measurement statistics for subsamples

\begin{tabular}{lcccccc}
\hline Variable & Mean & SD & AVE & CR & $\begin{array}{c}\text { Factor } \\
\text { loading }\end{array}$ & $\begin{array}{c}\text { Discriminant } \\
\text { validity }\end{array}$ \\
\hline A (N = 77) & & & & & & \\
TSQ & 4.81 & 1.04 & 0.433 & 0.703 & $0.62-0.90$ & 0.748 \\
PQ & 4.65 & 0.82 & 0.559 & 0.882 & $0.31-0.85$ & 0.604 \\
SQ & 5.00 & 0.91 & 0.421 & 0.796 & $0.42-0.87$ & 0.718 \\
BI & 4.94 & 0.90 & 0.515 & 0.909 & $0.45-0.85$ & 0.658 \\
B (N = 55) & & & & & & 0.692 \\
TSQ & 5.29 & 0.87 & 0.664 & 0.881 & $0.40-0.99$ & 0.810 \\
PQ & 5.03 & 1.28 & 0.479 & 0.821 & $0.41-0.88$ & 0.755 \\
SQ & 5.19 & 0.99 & 0.656 & 0.916 & $0.41-0.89$ & 0.815 \\
BI & 5.23 & 0.92 & 0.570 & 0.926 & $0.44-1.01$ & \\
C (N = 68) & & & & & & 0.702 \\
TSQ & 5.19 & 0.83 & 0.565 & 0.774 & $0.41-0.90$ & 0.604 \\
PQ & 5.50 & 0.65 & 0.493 & 0.840 & $0.45-0.95$ & 0.755 \\
SQ & 5.32 & 0.75 & 0.365 & 0.678 & $0.54-0.94$ & 0.752 \\
BI & 5.20 & 0.94 & 0.571 & 0.928 & $0.66-1.01$ & \\
\hline
\end{tabular}

Source: Authors' calculations. 


\subsection{Results for Overall Sample}

We analyze the regression results in three steps (Table 7). In the first step, we establish that all four relationships are positive and significant, that is, we accept $\mathrm{H} 1 \mathrm{~A}, \mathrm{H1B}, \mathrm{H} 2$ and $\mathrm{H} 3$ at $p<0.01$. TSQ and SQ have a significant relationship $(\beta=0.204)$. TSQ and PQ have a positive, significant relationship $(\beta=0.493)$. SQ and PQ are correlated with BI, with $\beta=0.332$ and $\beta=0.393$ at $p<0.01$.

Table 7: Standardized regression results with $B I$ as criterion variable

\begin{tabular}{|c|c|c|c|c|}
\hline Hypothesis & Overall & $\mathbf{A}$ & B & $\mathrm{C}$ \\
\hline & $\mathrm{N}=200$ & $\mathrm{~N}=77$ & $\mathrm{~N}=55$ & $\mathrm{~N}=68$ \\
\hline \multirow{2}{*}{\multicolumn{5}{|c|}{$\begin{array}{l}\text { Step 1: Integrating marketing and operations } \\
\text { H1: TSQ }\end{array}$}} \\
\hline & & & & \\
\hline H1A: TSQ and SQ & $0.204^{* * *}$ & $0.170^{* * *}$ & $0.435^{* * *}$ & $0.167^{* * *}$ \\
\hline H1B: TSQ and PQ & $0.493^{* * *}$ & $0.442^{* * *}$ & $0.780^{* * *}$ & $0.409^{* * *}$ \\
\hline $\mathrm{H} 2$ : SQ and BI & $0.332^{* * *}$ & $0.427^{* * *}$ & 0.336 & 0.637 \\
\hline H3: PQ and BI & $0.393^{* * *}$ & 0.328 & $0.605^{* * *}$ & $0.436^{* * *}$ \\
\hline \multicolumn{5}{|c|}{ Step 2: Accessibility (moderator) } \\
\hline \multicolumn{5}{|l|}{ H4A: High EA } \\
\hline TSQ and SQ & $0.224^{* * *}$ & $0.235^{* * *}$ & $1.337^{* * *}$ & $0.560^{* * *}$ \\
\hline TSQ and PQ & $0.619^{* * *}$ & 0.365 & $1.338^{* * *}$ & $1.428^{* * *}$ \\
\hline SQ and BI & $1.090^{* * *}$ & 0.177 & $0.545^{* * *}$ & -0.899 \\
\hline PQ and BI & 0.163 & 0.453 & $0.617^{* * *}$ & $1.894^{* * *}$ \\
\hline \multicolumn{5}{|l|}{ H4B: Low EA } \\
\hline TSQ and SQ & $0.115^{* * *}$ & 0.072 & $1.108^{* * *}$ & -0.028 \\
\hline TSQ and PQ & 0.350 & $0.382^{* * *}$ & $1.161^{* * *}$ & -0.062 \\
\hline SQ and BI & -0.094 & $0.874^{* * *}$ & 0.251 & $2.210^{* * *}$ \\
\hline PQ and BI & $0.394^{* * *}$ & $0.769^{* * *}$ & 0.598 & -1.328 \\
\hline \multicolumn{5}{|c|}{ Step 3: Customer attitudes to telephone ordering (moderator) } \\
\hline \multicolumn{5}{|l|}{ H5A: High ATT } \\
\hline TSQ and SQ & 0.067 & $0.311^{* * *}$ & $1.270^{* * *}$ & 0.820 \\
\hline TSQ and PQ & $0.493^{* * *}$ & $0.457^{* * *}$ & $1.298^{* * *}$ & $0.338^{* * *}$ \\
\hline SQ and BI & 0.029 & -0.196 & $0.524^{* * *}$ & -0.083 \\
\hline PQ and BI & 0.232 & 0.455 & $0.678^{* * *}$ & $1.801^{* * *}$ \\
\hline \multicolumn{5}{|l|}{ H5B: Low ATT } \\
\hline TSQ and SQ & $0.225^{* * *}$ & -0.810 & $1.136^{* * *}$ & -0.280 \\
\hline TSQ and PQ & $0.307^{* * *}$ & 0.144 & $1.184^{* * *}$ & -0.620 \\
\hline SQ and BI & $0.586^{* * *}$ & $0.311^{* * *}$ & 0.277 & $2.210^{* * *}$ \\
\hline PQ and BI & 0.101 & $0.382^{* * *}$ & 0.575 & -1.328 \\
\hline
\end{tabular}

Source: Authors' calculations. 
In the second step, we introduce EA as a moderating variable. The relationships between TSQ and SQ, TSQ and PQ, and SQ and PQ (leading to BI) are moderated by high EA and low EA. In the first case, the relationship between TSQ and SQ is positive and significant $(\beta=0.224$ at $p<0.01)$. In the second case, the relationship between TSQ and PQ is positive and significant $(\beta=0.619$ at $p<0.01)$. The relationship between SQ and BI is significant $(\beta=$ 1.090 at $p<0.01)$. When EA is low, only two relationships are positive and significant: TSQ and SQ $(\beta=0.115$ at $p<0.01)$ and PQ and BI $(\beta=0.394$ at $p<$ $0.01)$.

In the third step, we moderate all four relationships using ATT. When ATT is high, TSQ and PQ have a positive, significant relationship ( $\beta=$ 0.493 at $p<0.01)$. However, when ATT is low, TSQ has a significant relationship with SQ $(\beta=0.225$ at $p<0.01)$ and with $\mathrm{PQ}(\beta=0.307$ at $p<0.01)$, while SQ and BI have a significant relationship $(\beta=0.586$ at $p<0.01)$.

\subsection{Results for Subsamples}

Empirically testing the data by individual subsample gives us an overview of both categories of fast food restaurant: burgers/sandwiches and pizzas. The different choice of restaurants is supported by Teimoury and Fathi (2013).

\subsubsection{Restaurant $A$}

In the first step, we find that the relationships between TSQ and SQ and between TSQ and PQ are positive and significant $(\beta=0.17$ and 0.442 at $p<0.01$, respectively). SQ has a significant correlation with BI $(\beta=0.427$ at $p<0.01)$, but PQ and BI are insignificantly correlated. In the second step, when high EA moderates the relationship between TSQ and SQ, $\beta=0.235$ at $p<0.01$. When EA is low, TSQ and SQ have a significant, positive relationship $(\beta=0.382$ at $p<0.01)$. SQ and PQ are significantly correlated with BI ( $\beta=0.87$ and 0.76 at $p<0.01$, respectively). In the third step, when ATT is high, TSQ is significantly and positively correlated with PQ and SQ $(\beta=0.311$ and 0.457 at $p<0.01$, respectively). At a low ATT, SQ and PQ are significantly correlated with $\mathrm{BI}(\beta=0.311$ and 0.382 at $p<0.01$, respectively).

\subsubsection{Restaurant B}

In the first step, we find that the relationships between TSQ and SQ and between TSQ and PQ are positive and significant $(\beta=0.435$ and 0.780 at $p<0.01$, respectively). Unlike SQ, PQ has a significant correlation with BI $(\beta$ 
$=0.605$ at $p<0.01)$. In the second step, a high EA moderates these relationships as follows: TSQ and SQ $(\beta=1.337$ at $p<0.01)$, TSQ and PQ $(\beta=$ 1.338 at $p<0.01)$, SQ and BI $(\beta=10.545$ at $p<0.01)$, and PQ and BI $(\beta=0.617$ at $p<0.01)$. When EA is low, TSQ has significant and positive relationships with PQ and SQ ( $\beta=0.874$ and 0.769 at $p<0.01$, respectively). In the third step, when ATT is high, two relationships are significant: TSQ and SQ, and TSQ and PQ. With a low ATT, SQ and PQ are both significantly correlated with $\mathrm{BI}(\beta=0.311$ and 0.382 at $p<0.01)$.

\subsubsection{Restaurant $\mathrm{C}$}

In the first step, we find that the relationships between TSQ and SQ and between TSQ and PQ are positive and significant $(\beta=0.167$ and 0.409 at $p<0.01$, respectively). PQ is significantly correlated with $\mathrm{BI}(\beta=0.436$ at $p<$ 0.01 ), while SQ is insignificantly correlated with BI. In the second step, a high EA moderates these relationships as follows: TSQ and SQ $(\beta=0.560$ at $p<$ $0.01)$, TSQ and PQ $(\beta=1.428$ at $p<0.01)$, and PQ and BI $(\beta=1.894$ at $p<0.01)$. When EA is low, only SQ and BI have a significant, positive relationship ( $\beta=$ 2.210 at $p<0.01$ ). In the third step, when ATT is high, TSQ has a significant and positive correlation with PQ $(\beta=0.338$ at $p<0.01)$ while PQ is significantly correlated with $\mathrm{BI}(\beta=1.801$ at $p<0.01)$. SQ is significantly correlated with BI $(\beta=2.210$ at $p<0.01)$ when ATT is low.

\subsection{Discussion}

In examining the level of integration between marketing and operations in Pakistan's fast food delivery industry, we use the constructs TSQ, PQ, SQ and BI. Two additional variables, EA and ATT, moderate these relationships. We use descriptive statistics, correlation analysis and a structural equation model to gauge the integration between marketing and operations in the sample firms. A key finding of this study is that TSQ is not directly correlated with BI: instead, it is correlated with PQ and SQ, which are in turn correlated with BI. The results show how consumers perceive various components of fast food delivery. Analyzing the subsamples simultaneously gives an insight into customer perceptions of PQ (operational concern) and TSQ (marketing concern). The standardized regression results (Table 7) represent the relationships between the constructs and can also be used to analyze operational and marketing differences among the subsamples.

In the overall sample, the three quality constructs TSQ, PQ and SQ have a significant impact on customer BI, thus supporting hypotheses H1- 
3. TSQ is significantly correlated with PQ and SQ, both of which have a significant effect on BI. The results underscore the importance of these quality constructs. Moreover, the most significant relationship is between TSQ and PQ, which reflects the integration between marketing and operations. Given the significant relationships that exist between TSQ and SQ, TSQ and PQ, SQ and BI, and PQ and BI, we conclude that the model integrating operations and marketing in the fast food delivery industry (Figure 1) holds. In the presence of high EA, the relationships between TSQ and SQ, TSQ and PQ, and SQ and BI are strong, whereas the relationship between $\mathrm{PQ}$ and $\mathrm{BI}$ is not significant. When EA is low, there is a significant relationship between TSQ and SQ and PQ and BI. Finally, given a low ATT, there is a significant relationship between TSQ and SQ, and between TSQ and PQ.

Figures 2 and 3 illustrate the relationships among the variables (for the overall sample) when moderated by high and low EA, respectively.

\section{Figure 2: High EA as moderator variable}

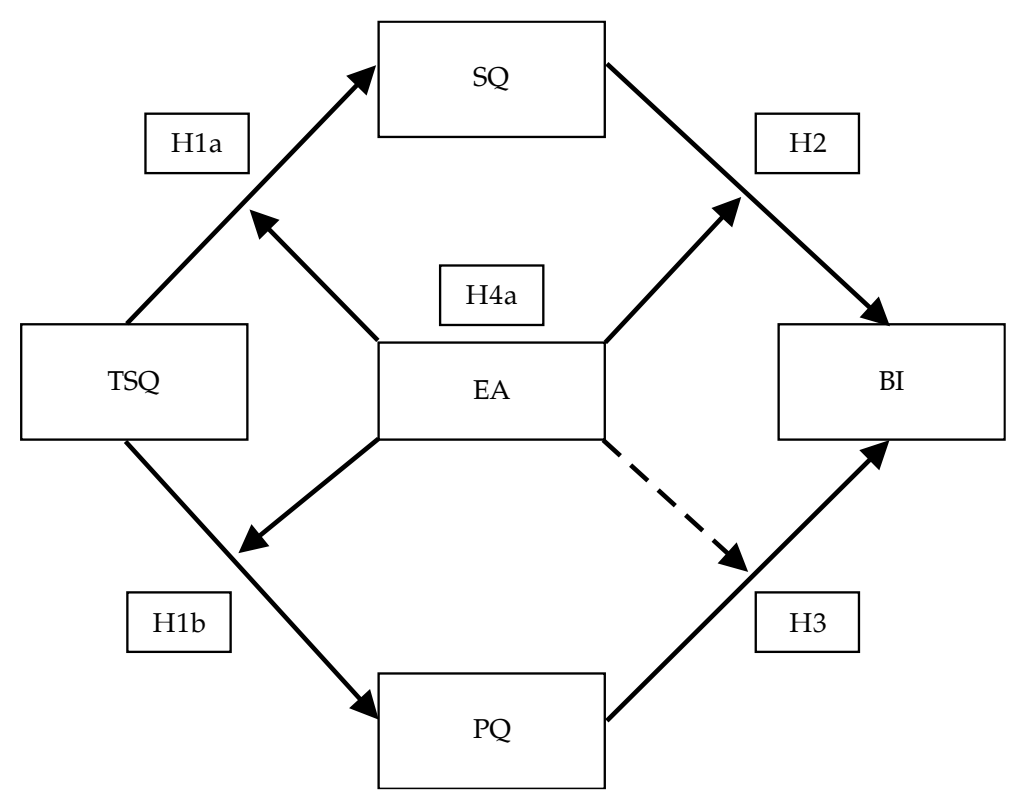

Note: Significant $=$ bold line, insignificant $=$ broken line, negative $=$ dotted line . 
Figure 3: Low EA as moderator variable

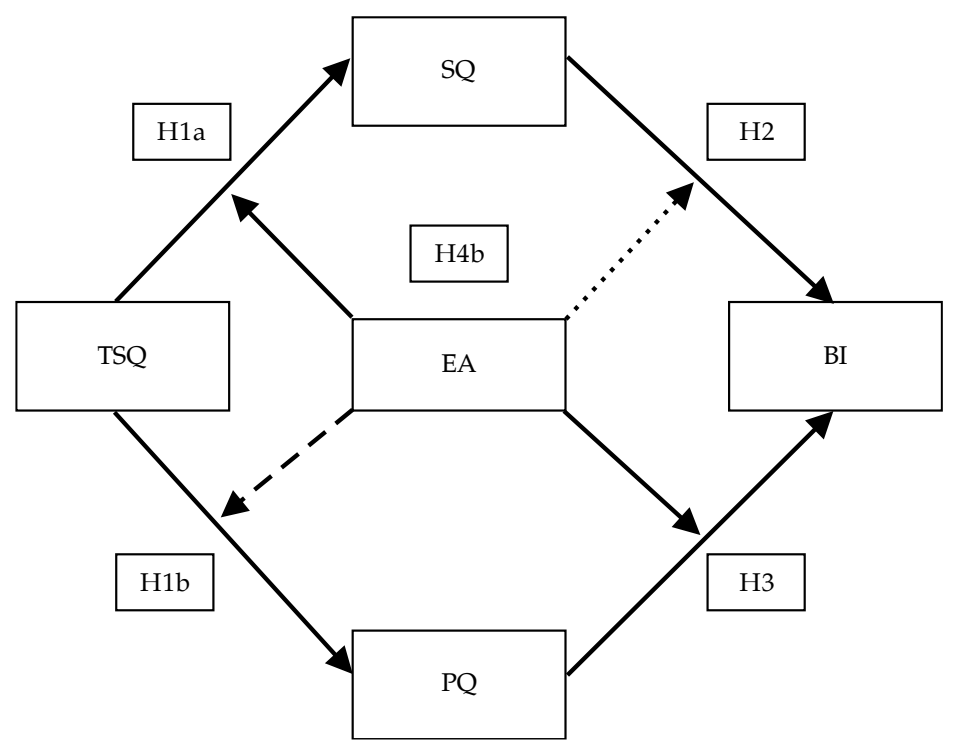

Note: Significant $=$ bold line, insignificant $=$ broken line, negative $=$ dotted line .

Figures 4 and 5 illustrate the relationships among the variables (for the overall sample) when moderated by high and low ATT, respectively.

\section{Figure 4: High ATT as moderator variable}

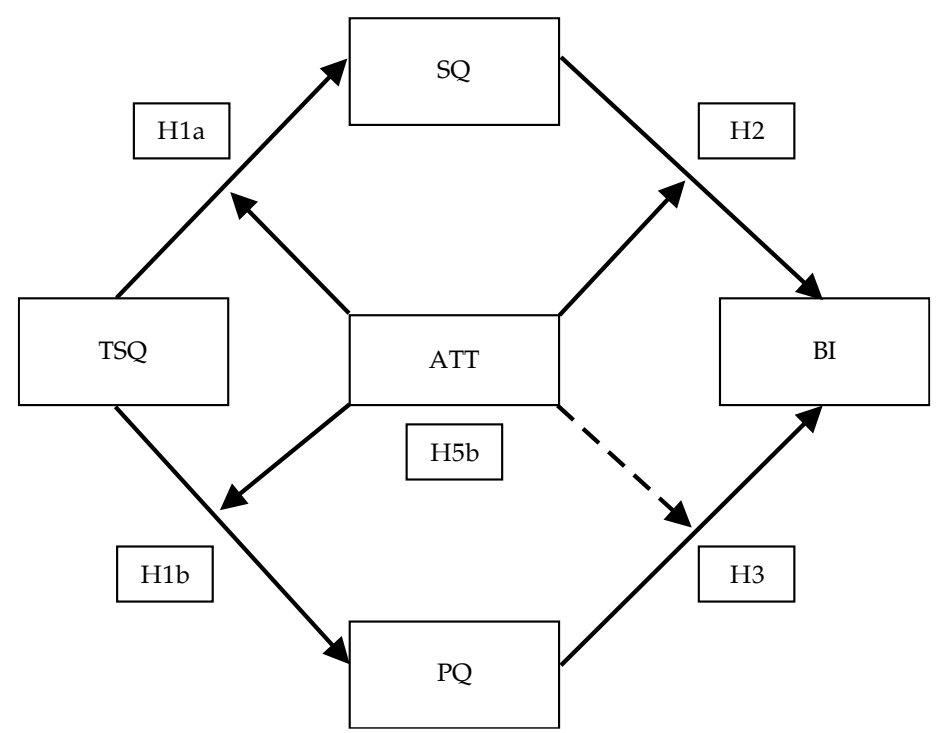

Note: Significant $=$ bold line, insignificant $=$ broken line, negative $=$ dotted line . 
Figure 5: Low ATT as moderator variable

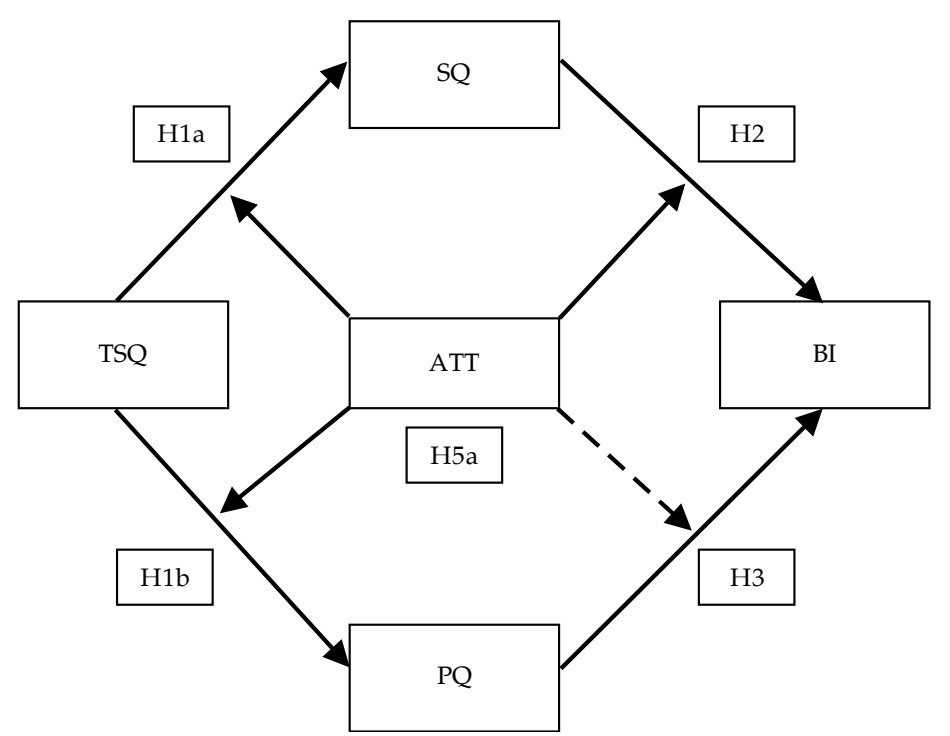

Note: Significant $=$ bold line, insignificant $=$ broken line, negative $=$ dotted line .

Given a high level of accessibility, restaurant A must focus on improving the quality of its service and telephone customer care in order to have a positive impact on customer BI. This implies that its customers value the quality of service and telephone customer care over the quality of the product itself.

Restaurant B does not have a significant relationship between PQ and BI; consumers appear to value the quality of telephone customer care as well as service provided. This result is supported by Table 1 where quick delivery and product quality are B's primary strategies. Given high levels of accessibility, all the constructs have a significant relationship with BI. These findings are in line with B's marketing strategy. When the ATT variable is low, there is a significant relationship between TSQ and SQ and between TSQ and PQ. This may be due to the restaurant's promotional delivery offers, which compensate for the low ATT.

Restaurant $\mathrm{C}$ has a negative relationship between SQ and BI, which implies that its consumers value the quality of the product over that of the service. This reflects its marketing strategy of delivering fresh pizza to the consumer quickly. When low accessibility moderates the relationship, only SQ seems to have a positive impact on BI. Given higher levels of accessibility, consumers value the quality of the product and telephone customer care over service. 


\section{Managerial and Research Implications}

Our findings provide some useful insights in the context of better marketing and operational strategies. Overall, the data in Table 7 indicates that consumers generally value fast food delivery services. The mean of BI (Table 5), which is the highest of the other values, supports this notion. As companies try to improve the quality of their telephone customer care, products and service in the presence of high accessibility, customers will have a more positive attitude to telephone ordering, reflected in a positive BI.

When fast food restaurants cannot offer high-quality telephone customer care, then they must use product or promotional offers to attract consumers. Fast food consumers may be more willing to compromise on the quality of the food if they are guaranteed a quick and efficient delivery service, which implies that companies must reduce their delivery window. This integration between marketing and operations will help the business become more successful. Thus, when consumers are willing to forego a particular attribute of performance or quality or a moderating variable, they are likely to want something else that gives them value for money. All elements of quality - the product, the service and customer care - need to be synergized rather than focusing on just one or two. The most interesting findings arise from a comparison across the subsamples. Table 8 shows which aspects each restaurant should pay attention to.

\section{Table 8: Study implications for subsamples}

\begin{tabular}{|c|c|c|}
\hline Restaurant & Concern & Focus \\
\hline $\mathrm{A}$ & $\begin{array}{l}\text { Accessibility, customer attitudes to } \\
\text { telephone ordering, product quality }\end{array}$ & Marketing and operations \\
\hline B & Service quality & Operations \\
\hline $\mathrm{C}$ & $\begin{array}{l}\text { Service quality, accessibility, customer } \\
\text { attitudes to telephone ordering }\end{array}$ & Marketing and operations \\
\hline
\end{tabular}

This study has several limitations. First, it is context-specific and thus not necessarily replicable for other countries. Second, in-depth interviews with managers engaged in marketing and operations would provide stronger qualitative insights into the managerial side of the integration process between marketing and operations - in this case, we have focused solely on the consumer's perspective of each organization's marketing communications and efficiency of delivery. Third, the data used is cross-sectional; it would be interesting to examine longitudinal data, which may not establish the causality between integration and its effectiveness, but would provide a 
before/after scenario and help understand changing trends in the fast food delivery industry. Finally, other factors such as price and packaging could also be included in the model: price, for example, acts as a distinguishing factor in the impact on BI. 


\section{References}

Agarwal, R., \& Prasad, J. (1999). Are individual differences germane to the acceptance of new information technologies? Decision Sciences, 30(2), 361-391.

Bailey, J. P. (1998). Electronic commerce: Prices and consumer issues for three products: Books, compact discs and software. Report prepared for the Working Party on the Information Economy. Paris: OECD.

Boulding, W., Kalra, A., \& Staelin, R. (1999). The quality double whammy. Marketing Science, 18(4), 463-484.

Boyer, K. K., \& Hult, G. T. (2005). Extending the supply chain: Integrating operations and marketing in the online grocery industry. Journal of Operations Management, 23(6), 642-661.

Boyer, K. K., \& Olson, J. R. (2002). Drivers of Internet purchasing success. Production and Operations Management, 11(4), 480-498.

Brucks, M., Zeithaml, V. A., \& Naylor, G. (2000). Price and brand name as indicators of quality dimensions for consumer durables. Journal of the Academy of Marketing Science, 28(3), 359-374.

Cronin, J. J., Brady, M. K., \& Hult, G. M. (2000). Assessing the effects of quality, value and customer satisfaction on consumer behavioral intentions in service environments. Journal of Retailing, 76(2), 193-218.

Cronin, J. J., \& Taylor, S. A. (1992). Measuring service quality: A reexamination and extension. Journal of Marketing, 56(3), 55-68.

Crosby, L. A., Evans, K. R., \& Cowles, D. (1990). Relationship quality in services selling: An interpersonal influence perspective. Journal of Marketing, 54(3), 68-81.

Crosby, P. B. (1979). Quality is free: The art of making quality certain. New York, NY: McGraw-Hill.

Erickson, G. M. (2011). A differential game model of the marketingoperations interface. European Journal of Operational Research, 211(2), 394-402. 
Feng, Y., D'Amours, S., \& Beauregard, R. (2008). The value of sales and operations planning in oriented strand board industry with maketo-order manufacturing system: Cross-functional integration under deterministic demand and spot market recourse. International Journal of Production Economics, 115(1), 189-209.

Fornell, C. (1992). A national customer satisfaction barometer: The Swedish experience. Journal of Marketing, 56(1), 6-21.

Fornell, C., \& Larcker, D. F. (1981). Evaluating structural equation models with unobservable variables and measurement error. Journal of Marketing Research, 18(1), 39-50.

Fournier, S., \& Mick, D. G. (1999). Rediscovering satisfaction. Journal of Marketing, 63(4), 5-23.

Garvin, D. (1988). Managing quality: The strategic and competitive edge. New York, NY: Free Press.

Glanz, K., Basil, M., Maibach, E., Goldberg, J., \& Snyder, D. (1998). Why Americans eat what they do: Taste, nutrition, cost, convenience and weight control concerns as influences on food consumption. Journal of the American Dietetic Association, 98(10), 1118-1126.

Gwinner, K. P., Gremler, D. D., \& Bitner, M. J. (1998). Relational benefits in services industries: The customer's perspective. Journal of the Academy of Marketing Science, 26(2), 101-114.

Hair, J. F., Black, W. C., Babin, B. J., Anderson, R. E., \& Tatham, R. L. (2006). Multivariate data analysis (6 $6^{\text {th }}$ ed.). Upper Saddle River, NJ: Pearson.

Harris, L. C., \& Goode, M. M. (2004). The four levels of loyalty and the pivotal role of trust: A study of online service dynamics. Journal of Retailing, 80(2), 139-158.

Hartline, M. D., \& Ferrell, O. C. (1996). The management of customercontact service employees: An empirical investigation. Journal of Marketing, 60(4), 52-70.

Ho, T. H., \& Zheng, Y.-S. (2004). Setting customer expectation in service delivery: An integrated marketing-operations perspective. Management Sciences, 50(4), 479-488. 
Innis, D. E., \& La Londe, B. J. (1994). Customer service: The key to customer satisfaction, customer loyalty and market share. Journal of Business Logistics, 15(1), 1-27.

Ioannidis, S., \& Kouikoglou, V. (2008). Revenue management in singlestage CONWIP production systems. International Journal of Production Research, 46(22), 6513-6532.

Kelley, S., \& Davis, M. (1994). Antecedents to customer expectations for service recovery. Journal of the Academy of Marketing Science, 22(1), 52-61.

Lambert, D. M., \& Stock, J. R. (1993). Strategic logistics management. Chicago, IL: Irwin.

Lee, H. L., \& Whang, S. (2001). E-business and supply chain integration (White Paper No. 2). Stanford, CA: Stanford Global Supply Chain Management Forum.

Lovelock, C. H. (1983). Classifying services to gain strategic marketing insight. Journal of Marketing, 47(3), 9-20.

McDougall, G. H., \& Levesque, T. (2000). Customer satisfaction with services: Putting perceived value into the equation. Journal of Services Marketing, 14(5), 392-410.

Mentzer, J. T., Gomes, R., \& Krapfel, R. E. (1989). Physical distribution service: A fundamental marketing concept? Journal of the Academy of Marketing Science, 17(1), 53-62.

Narver, J. C., \& Slater, S. F. (1990). The effect of a market orientation on business profitability. Journal of Marketing, 54(4), 20-35.

O'Leary-Kelly, S. W., \& Flores, B. E. (2002). The integration of manufacturing and marketing/sales decisions: Impact on organizational performance. Journal of Operations Management, 20(3), 221-240.

Oliva, R., \& Watson, N. (2011). Cross-functional alignment in supply chain planning: A case study of sales and operations planning. Journal of Operations Management, 29(5), 434-448. 
Olsen, W. K. (2004). Moderating variable. In M. S. Lewis-Beck, A. Bryman \& T. F. Liao (Eds.), The SAGE encyclopedia of social science research methods (p. 29). New York, NY: SAGE.

Rao, V. R. (2009). Handbook of pricing research in marketing. Cheltenham: Edward Elgar.

Ray, S. (2005). An integrated operations-marketing model for innovative products and services. International Journal of Production Economics, 953, 327-345.

Reichheld, F. (1996). Learning from customer defections. Harvard Business Review, 74, 56-69.

Reichheld, F., \& Sasser, W. E. (1990). Zero defections: Quality comes to services. Harvard Business Review, 68, 105-111.

Roth, A. V., \& Van Der Velde, M. (1991). Operations as marketing: A competitive service strategy. Journal of Operations Management, 10(3), 303-328.

Schlesinger, L., \& Heskett, J. (1991). Breaking the cycle of failure in services. Sloan Management Review, 32(3), 17-28.

Schlosser, E. (2012). Fast-food nation: The dark side of the all-American meal. Boston, MA: Houghton Mifflin Harcourt.

Stank, T., Crum, M., \& Arango, M. (1999). Benefits of interfirm coordination in food industry supply chains. Journal of Business Logistics, 20(2), 21-41.

Sulek, J. M., \& Hensley, R. L. (2004). The relative importance of food, atmosphere and fairness of wait: The case of a full-service restaurant. Cornell Hospitality Quarterly, 45(3), 235-247.

Tang, C. S. (2010). A review of marketing-operations interface models: From coexistence to coordination and collaboration. International Journal of Production Economics, 125(1), 22-40.

Teimoury, E., \& Fathi, M. (2013). An integrated operations-marketing perspective for making decisions about order penetration point in multi-product supply chain: A queuing approach. International Journal of Production Research, 51(18), 5576-5596. 
Vandaele, N., \& Perdu, L. (2010, June). The operations-finance interface: An example from lot sizing. Paper presented at the 7 th International Conference on Services Systems and Services Management, Tokyo.

Yrjola, H. (2001). Physical distribution considerations for electronic grocery shopping. International Journal of Physical Distribution and Logistics Management, 31(10), 746-761.

Zeithaml, V. A. (1988). Consumer perceptions of price, quality and value: A means-end model and synthesis of evidence. Journal of Marketing, 52(3), 2-22.

Zeithaml, V. A., Berry, L., \& Parasuraman, A. (1996). The behavioral consequences of service quality. Journal of Marketing, 60(2), 31-46. 
Appendix

\section{Survey Questionnaire}

Which fast food restaurant do you order from most often?

McDonald's KFC Pizza Hut

Telephone customer service quality (TSQ)

TSQ1 It is easy for me to remember how to perform tasks using XYZ's toll-free/helpline number.

TSQ2 It is easy to get XYZ's toll-free/helpline number to do what I want.

TSQ3 My interaction on XYZ's toll-free/helpline number is clear and understandable.

TSQ4 Overall, I believe that XYZ's toll-free/helpline number is easy to use.

TSQ5 XYZ's toll-free/helpline number is easy to navigate.

TSQ6 XYZ's toll-free/helpline number has a logical sequence of steps for placing an order.

TSQ7 XYZ's toll-free/helpline number is easy to search for.

Product quality (PQ)

PQ1 XYZ offers prestigious (high-quality) products.

PQ2 XYZ has an excellent assortment of products.

PQ3 XYZ's products are among the best.

PQ4 XYZ has a sufficient range of product choices (I can get what I want).

PQ5 XYZ's products are of the same quality as I can buy at a store.

PQ6 The number of substitutions or out-of-stock items is reasonable.

Service quality $(S Q)$

SQ1 XYZ's employees are reliable in providing the service I expect.

SQ2 XYZ's employees understand my service needs.

SQ3 XYZ's employees are responsive to my service requests.

SQ4 XYZ's employees are competent in providing the expected service.

SQ5 I feel secure in my service encounters with XYZ's employees. 
SQ6 XYZ's employees are courteous when providing me service.

SQ7 XYZ's employees are accessible enough to answer my questions.

SQ8 The tangible aspects of XYZ's service (appearance of delivery vans, staff, products, etc.) are excellent.

SQ9 XYZ has good credibility in providing the service I need.

SQ10 I can communicate easily with XYZ regarding my service needs.

Accessibility (EA)

EA1 I can dial the toll-free/helpline number when I want to.

EA2 The call is answered quickly (I don't have to wait long for new material).

Attitudes to phone ordering (ATT)

ATT1 I like using phone-ordering services.

ATT2 Phone-ordering services are fun to use.

ATT3 Phone-ordering is an attractive ordering method.

Behavioral intention (BI)

BI1 I would classify myself as a loyal customer of XYZ.

BI2 I do not expect to switch to another company to get better service in the future.

BI3 I would continue to shop at XYZ even if I had to pay more.

BI4 I would complain to other customers if I experienced a problem with XYZ's service.

BI5 I would complain to XYZ's employees if I experienced a problem with their service. 